\title{
ASTRONOMY EDUCATION IN THE EAST
}

\author{
SYUZO ISOBE \\ National Astronomical Observatory, Mitaka Tokyo 181 Japan \\ isobesz@cc.nao.ac.jp
}

\section{Teaching of astronomy in Asian-Pacific region}

In the IAU, there is the Commission 46 "Teaching of Astronomy" to which at least one representative from each member country belongs. At an occasion of the Asian-Pacific regional meeting of the IAU held in Beijing in 1987, there was a resolution to set up a committee of Teaching of Astronomy in the Asian-Pacific region. Since then, a session of the Teaching of Astronomy has been hold at each regional meeting.

A special colloquium on the Teaching of Astronomy in the Asian-Pacific region was held in Beijing in October, 1993. Bulletin of the Teaching of Astronomy in the Asian-Pacific region was published from No.1 to No.12. All the activities are tightly related to recent features of astronomical education in the East. Referring to these papers and to reports of national representatives of the Commission 46, a brief view of astronomical education in the East is shown in this paper.

\section{School education systems in the East}

School education systems in the East are similar within countries in the area: 6 years elementally school, 3 years junior high school, and 3 years senior high school. The first 9 years are compulsory. In Korea and Japan, Nature or Science is taught with a credit of 3 or 4 at an elementary school and a junior high school, but pupils at a senior high school start to choose subjects out of Physics, Chemistry, Biology, and Earth Science.

In an elementary school, fundamental and basic items of science are taught. For a case of astronomy, these are diurnal motion of the sun, the phase of the moon, shadow length, and so on, which are not attractive for school pupils. It is said that pupils start to dislike science at their elementary school period, and this becomes a big problem of each country.

\section{Target of astronomical education}

What is a target of astronomical education? At a time of 1988, I present a diagram showing a number distribution of people who have different levels of interest in astronomy (Isobe 90). A:10 people produce useful observational data, $\mathrm{B}: 10^{3}$ people observe frequently, C: $10^{4}$ people observe several times per year, D: $10^{5}$ people read astronomical magazines, $\mathrm{E}: 10^{6}$ people read general science magazine, $\mathrm{F}: 10^{7}$ people read scientific articles in newspapers, G:10 $0^{8}$ people have no interest in science. Our target is not to bring $10^{8}$ people to a category $\mathrm{A}$, but to categories $\mathrm{D}$ or $\mathrm{E}$, who will not only support scientific activities but also have an ability to evaluate global environmental problems scientifically.

Because of recent quick scientific and engineering cievelopment, science is divided into many parts such as astrophysics, geophysics, mineralogy, solid physics, biochemistry, and so on. It becomes very hard for one scientist working in a field to understand all the field globally.

However, each phenomenon seen daily by school pupils is combined with different scientific fields. It is not better to teach astronomy itself but scientific matter combined with astronomy. 


\section{Method of western science to eastern science}

To proceed science, one should solve a problem to be divided into building blocks which can be analyzed. However, each building block would not be attractive for school pupils because it seems to be far from real world. Therefore, pupils loose their interest in science. Real nature is much complicated because many building blocks intertwine each other but pupils see it daily.

In the western science, one shoots a direction where he believe a truth is, when he try to find the truth. On the other hand, in the eastern, one traps a truth within a big net. The truth is within the net but he does not know where it is.

We have followed the western way to teach science. However, newly discovered scientific outputs have been too much specialized and general people have a difficulties to catch those idea. Now, I propose for us to introduce the eastern way. Then, people, especially school pupils are able to catch global ideas of problems scientifically. The details of this proposal is shown in my previous paper (1996).

\section{References}

Isobe,S.,1990, The Teaching of Astronomy: IAU Colloquium No.105, ed by J.M.Pasachoff and J.R.Percy (Cambridge University Press, Cambridge), pp.103-107.

Isobe,S.,1996, J.Korean A.S., 29, 451-453. 